\title{
Developmental Changes in Murine Brain Antioxidant Enzymes
}

\author{
JANINE Y. KHAN AND STEPHEN M. BLACK \\ Division of Neonatology, Departments of Pediatrics [J.Y.K., S.M.B.] and Molecular Pharmacology \\ [S.M.B.] Northwestern University School of Medicine, Chicago, Illinois 60611, U.S.A.
}

\begin{abstract}
ABST
Reactive oxygen species produced in cells during normal
aerobic metabolism have the ability to induce lipid peroxidation
and protein oxidation; therefore, their detoxification and elimi-
nation are necessary for physiologic cellular activity and sur-
vival. The changes in neuronal antioxidant enzymes from fetal
life to adulthood have not been fully described. We investigated
protein expression, using Western blot analysis, and enzymatic
activity of the antioxidant system-copper-zinc superoxide dis-
mutase (SOD), manganese SOD, catalase, and glutathione per-
oxidase, as well as reduced glutathione level as an indicator of
the nonenzymatic system-in CD1 murine brain at embryonic d
18 (E18), and postnatal d 1 (P1), d 4, d 7, d 14, and d 21.
Copper-zinc SOD and glutathione peroxidase protein levels were
low, whereas manganese SOD and catalase protein levels were
high at E18 and P1. Total SOD activity was high at E18 and P1
and paralleled elevated manganese SOD activity; however, cop-
per-zinc SOD activity was relatively unchanged throughout de-
velopment. Catalase activity doubled and glutathione peroxidase
activity tripled between E18 and P1. Reduced glutathione in-
creased between E18 and P1. Except for catalase and manganese
SOD, peak protein levels do not occur until later developmental
\end{abstract}
ages. We suggest that as the fetus moves from an in utero hypoxic to a relatively hyperoxic environment with an approximate 4-fold elevation in oxygen concentration, these developmental changes in antioxidant enzymes are compensatory mechanisms aimed at protecting the newborn from oxidative stress. These data will be important in our future understanding of the mechanisms by which hypoxia mediates injury in the immature and the mature brain. (Pediatr Res 54: 77-82, 2003)

$\quad$ Abbreviations
SOD, superoxide dismutase
CuZnSOD, copper-zinc SOD
MnSOD, manganese SOD
GPx, glutathione peroxidase
GSH, glutathione
ROS, reactive oxygen species
$\mathbf{H}_{2} \mathbf{O}_{2}$, hydrogen peroxide
E18, embryonic d 18
P1, P2, P4, P7, P14, P21, postnatal d 1, 2, 4, 7, 14, 21
DTPA, diethylenetriaminepentaacetic acid
Pao $_{2}$, arterial partial pressure of oxygen

ROS are continuously produced in mammalian cells during normal aerobic metabolism, and represent a class of biologically generated species that threaten neuronal survival by their ability to induce lipid peroxidation, protein oxidation, and DNA damage (1-3). These free radicals are processed by a highly complex and integrated antioxidant defense system that is composed of the enzymes CuZnSOD, MnSOD, catalase, GPx, and glutathione reductase, as well as nonenzymatic substances such as vitamins A, C, and E and low molecular weight molecules including reduced GSH. The SODs constitute the first line of defense against the deleterious effects of ROS.

Received August 1, 2002; accepted January 24, 2003.

Correspondence: Stephen M. Black, Ph.D., Department of Pediatrics and Molecular Pharmacology, Northwestern University, Ward 12-191, 303 East Chicago Avenue, Chicago, IL 60611, U.S.A.; e-mail: steveblack@northwestern.edu

Supported in part by grants HL60190, HL67841, and HD398110 from the National Institutes of Health, FY00-98 from the March of Dimes, and 0051409Z from the American Heart Association, Midwest Affiliate (all to S.M.B.).

DOI: 10.1203/01.PDR.0000065736.69214.20
CuZnSOD is a key cytosolic enzyme, whereas MnSOD is present in high concentration in the mitochondria. Under physiologic conditions, the mitochondria are the most important source of the superoxide radical (4). Mitochondrial MnSOD, therefore, plays a significant protective role in neurons at a major site of ROS production. SOD enzymatically scavenges superoxide, converting it to $\mathrm{H}_{2} \mathrm{O}_{2}$, which is subsequently catabolized to water by catalase, GPx, and GSH reductase. $\mathrm{H}_{2} \mathrm{O}_{2}$ is constantly generated in cells, and the predominant biochemical source of $\mathrm{H}_{2} \mathrm{O}_{2}$ in the brain appears to be through reactions catalyzed by SOD.

The detoxification of ROS is especially important for the brain because neurons have been shown to be particularly vulnerable to oxidative stress as a result of the limited ability of the neuronal GSH system to protect against increasing endogenous $\mathrm{H}_{2} \mathrm{O}_{2}$ production (5). Reduced $\mathrm{GSH}$, which acts as a substrate for GPx, is now known to play an important role in neuronal detoxification of ROS, thereby minimizing the effect of oxidative stress. A deficiency of reduced GSH contributes to 
cerebral mitochondrial damage and may continue to exacerbate the adverse effects caused by other cerebral insults, for example, hypoxia-ischemia or stroke $(6,7)$.

The corresponding changes in protein levels and enzyme activities of the antioxidant defense system, from fetal life to adulthood, have not been fully described. Thus, we hypothesized that there is a physiologic mechanism by which the brain protects itself from the surge in oxygen concentration encountered after delivery, which results in an increase in oxidative metabolism and, of course, increased free radical generation.

\section{METHODS}

Animals. CD1 mice were purchased from Harlan Laboratories and housed in individual cages in a temperature controlled environment with a 12-h light-dark cycle with access to water and standard chow ad libitum. The care and use of animals followed the guidelines established by the National Institutes of Health and were approved by the Northwestern University Animal Care and Use Committee.

Sample collection. Timed-pregnant female mice were obtained at $16 \mathrm{~d}$ gestation, with the length of gestation in the mouse being approximately $20 \mathrm{~d}$. E18 brains were obtained after maternal hysterectomy under i.p. pentobarbital sodium anesthesia. Two pooled E18 brains were used for each sample for protein analysis. For postnatal animals at $1,4,7,14$, and $21 \mathrm{~d}$, individual whole brains were used from six different litters $(n=6)$, and the same litters were used for all analyses. Brain tissue, including the cerebral cortex and cerebellum, removed from postnatal animals under i.p. pentobarbital sodium anesthesia were stored at $-70^{\circ} \mathrm{C}$ for various analyses. P21 was used as the adult reference because at this age the mouse has fully developed reproductive capability with advanced brain development.

Western blot analysis. Twenty micrograms of brain homogenates were solubilized in Laemmli's buffer. Protein content was determined by Bradford's dye-binding assay (8). The samples were then separated on $12 \%$ discontinuous SDSpolyacrylamide gel and transferred to a nitrocellulose filter at room temperature by electroblotting. Transferred filters were treated with Blotto solution [5\% milk powder $(\mathrm{wt} / \mathrm{vol})$ in Tris-buffered saline (TBS)-Tween] for $2 \mathrm{~h}$ at room temperature and then incubated for $1-2 \mathrm{~h}$ at room temperature with an affinity-purified primary antibody to CuZnSOD, MnSOD, catalase, or GPx 4 at a dilution of 1:1000. The primary antigenantibody complex was identified with a secondary antibody, goat anti-rabbit $\operatorname{IgG}$ (Pierce). After incubation for $2 \mathrm{~h}$ at room temperature, the filters were extensively washed and exposed to enhanced chemiluminescence (ECL) Western blotting detection reagents at room temperature using the horseradish peroxidase $-\mathrm{H}_{2} \mathrm{O}_{2}$-catalyzed oxidation of luminol in alkaline conditions. After oxidation, the luminol is in an excited state, which then decays to ground state via a light-emitting pathway. The maximum light emission is at a wavelength of $428 \mathrm{~nm}$. The filter was then placed in the Kodak imager to capture the bands, which were quantitated by densitometry performed using the KDS ID 3.01 program.

Estimation of reduced GSH levels. Reduced GSH level was measured as previously described by Anderson (9). Tissue was perfused with $0.9 \% \mathrm{NaCl}$ containing $0.16 \mathrm{U} / \mathrm{mL}$ heparin, then washed in ice-cold $0.9 \% \mathrm{NaCl}$. Tissue was minced in ice-cold $5 \%$ meta phosphoric acid (MPA) at 5\% wt/vol and subsequently homogenized. The GSH assay kit (Calbiochem, San Diego, CA, U.S.A.) was used to determine GSH level. The homogenate was centrifuged at $3000 \times g$ for $10 \mathrm{~min}$ at $4^{\circ} \mathrm{C}$. Sample containing $40 \mu \mathrm{g}$ of protein was adjusted to a total volume of $900 \mu \mathrm{L}$ with buffer and incubated at $25^{\circ} \mathrm{C}$ for 10 min in the dark with $800 \mu \mathrm{L}$ of $200 \mathrm{mM}$ potassium phosphate, $\mathrm{pH} 7.8$, containing $0.2 \mathrm{mM}$ DTPA, and $0.025 \%$ LUBROL, followed by $50 \mu \mathrm{L}$ of $12 \mathrm{mM}$ solution of chromogenic reagent in $0.2 \mathrm{~N} \mathrm{HCl}$, and finally $50 \mu \mathrm{L}$ of $30 \% \mathrm{NaOH}$. Final absorbance was measured at $400 \mathrm{~nm}$ for $30 \mathrm{~s}$.

SOD spectrophotometric assay. Total SOD activity was measured using Oxis Biotech SOD-525 spectrophotometric assay. SODs are metalloenzymes that catalyze the dismutation of superoxide anion as follows:

$$
2 \mathrm{O}_{2}{ }^{-}+2 \mathrm{H}^{+} \stackrel{\mathrm{SOD}}{\longrightarrow} \mathrm{H}_{2} \mathrm{O}_{2}+\mathrm{O}_{2}
$$

Tissue was washed with $0.9 \% \mathrm{NaCl}$ containing $0.16 \mathrm{U} / \mathrm{mL}$ heparin to remove red blood cells, followed by homogenization in buffer containing 1:1.55 $\mathrm{KH}_{2}: \mathrm{Na}_{2}, \mathrm{pH}$ 7.0. Sample containing $40 \mu \mathrm{g}$ of protein was added to buffer 2-amino-2-methyl1,3-propanediol, $50 \mathrm{mM}$, containing $3.3 \mathrm{mM}$ boric acid and $0.11 \mathrm{mM}$ DTPA, $\mathrm{pH} 8.8$, at $37^{\circ} \mathrm{C}$ for a final volume of $940 \mu \mathrm{L}$. Thirty microliters of 1,4,6-trimethyl-2-vinylpyridinium trifluoromethanesulfonic acid, $33.3 \mathrm{mM}$, in $1 \mathrm{mM} \mathrm{HCl}$ was added, and the mixture was incubated at $37^{\circ} \mathrm{C}$ for $1 \mathrm{~min}$. To this mixture was added $30 \mu \mathrm{L}$ of $5,6,6 \alpha, 11 \beta$-tetrahydro-3,9,10trihydroxybenzo[c]fluorine, $0.66 \mathrm{mM}$, in $32 \mathrm{mM} \mathrm{HCl}$ containing $0.5 \mathrm{mM}$ DTPA and $2.5 \%$ ethanol. The final mixture was immediately transferred to a spectrophotometric cuvette, and the absorbance was measured at $525 \mathrm{~nm}$ for $30 \mathrm{~s}$ to give total SOD activity.

CuZnSOD activity was measured using ethanol-chloroform extraction, which inactivates MnSOD. The extraction reagent consisted of ethanol/chloroform 62.5/37.5 (vol/vol). Four hundred micrograms of cold extraction reagent was added to 250 $\mu \mathrm{L}$ of sample and centrifuged at $3000 \times g$ at $4^{\circ} \mathrm{C}$ for $5 \mathrm{~min}$. The upper aqueous layer was collected and subjected to protein estimation. Samples containing $40 \mu \mathrm{g}$ of protein were added to the above buffer and analyzed as described above. CuZnSOD absorbance was measured at $525 \mathrm{~nm}$ for $30 \mathrm{~s}$.

MnSOD activity was calculated by subtracting CuZnSOD activity from total SOD activity

Catalase assay. Catalase catalyzes the following reactions: decomposition of $\mathrm{H}_{2} \mathrm{O}_{2}$

$$
\left(2 \mathrm{H}_{2} \mathrm{O}_{2} \stackrel{\text { catalase }}{\longrightarrow} 2 \mathrm{H}_{2} \mathrm{O}+\mathrm{O}_{2}\right)
$$

oxidation of $\mathrm{H}$ donors

$$
\left(\mathrm{ROOH}+\mathrm{AH}_{2} \stackrel{\text { catalase }}{\longrightarrow} \mathrm{H}_{2} \mathrm{O}+\mathrm{ROH}+\mathrm{A}\right)
$$


The enzymatic decomposition of $\mathrm{H}_{2} \mathrm{O}_{2}$ is a first-order reaction that is always proportional to the peroxide concentration (10). Tissue was prepared in assay buffer containing $1: 1.55$ $\mathrm{KH}_{2}: \mathrm{Na}_{2}$ (pH 7.0). Each sample containing $40 \mu \mathrm{g}$ of protein was added to $1 \mathrm{~mL}$ of buffer and $1 \mathrm{~mL}$ of $\mathrm{H}_{2} \mathrm{O}_{2}$ solution. Absorbance was measured at $260 \mathrm{~nm}$ at room temperature for $30 \mathrm{~s}$.

GPx activity. Total GPx activity was measured using the method of Paglia and Valentine (11). Whole brain was homogenized in Tris-HCl, $\mathrm{pH} 7.2$, (vol 3:1). Homogenate was centrifuged at $3000 \times g$ for $10 \mathrm{~min}$ at $4{ }^{\circ} \mathrm{C}$. Supernatant was removed and further centrifuged at $12,000 \times g$ for $15 \mathrm{~min}$ at $4^{\circ} \mathrm{C}$. Samples containing $40 \mu \mathrm{g}$ of protein were added to the assay buffer consisting of $100 \mathrm{mM}$ Tris- $\mathrm{HCl}, \mathrm{pH} 7.2,3 \mathrm{mM}$ EDTA, $1 \mathrm{mM}$ sodium azide (Sigma Chemical Co, St. Louis, MO, U.S.A.), $1.2 \mathrm{mM}$ cumene hydroperoxide, $0.5 \mathrm{mM}$ NADPH, 1 unit GSH reductase (Sigma Chemical Co) in a final volume of $1 \mathrm{~mL}$. The rate of NADPH oxidation was measured spectrophotometrically at $340 \mathrm{~nm}$. Selenium-dependent GPx activity was measured using a similar technique, using 0.25 $\mathrm{mM} \mathrm{H} \mathrm{H}_{2} \mathrm{O}_{2}$ instead of cumene hydroperoxide in the assay buffer. Nonselenium-dependent GPx activity was calculated by subtracting the value for selenium-dependent GPx activity from total GPx activity.

Data analysis. All data are shown as mean + SEM. Oneway ANOVA was used to determine the presence of differences, and intergroup differences were validated by the Newman-Keuls test.

\section{RESULTS}

Table 1 provides the brain weights at the different ages examined, and as expected, an age-dependent increase is noted. Quantitation of CuZnSOD and MnSOD protein levels in brain homogenates from developmental ages E18, P1, P4, P7, P14, and $\mathrm{P} 21$ for CuZnSOD and MnSOD is shown in Figures $1 A$ and $2 A$, respectively. CuZnSOD protein level was low at E18, increasing to $60 \%$ of $\mathrm{P} 21$ level at P1 $(p<0.05)$, with a subsequent steady increase to P21 control. In contrast, MnSOD protein level was higher at E18 than P21 with peak expression at $\mathrm{P} 7$, then a decrease to the P21 control. Total SOD (CuZnSOD and MnSOD) activity was highest at E18 and P1, with a subsequent decline of $50 \%$ at $\mathrm{P} 4$ and a continued downward trend to P21. Although an increasing trend is demonstrated between $\mathrm{E} 18$ and P1, this was not statistically significant. SOD activity at E18 was 2-fold and at P1, 3-fold higher than P21 control. MnSOD activity paralleled changes in total SOD

Table 1. Animal demographics

\begin{tabular}{lc}
\hline Age & Brain weights $(\mathrm{mg})$ \\
\hline E18 & $71.4 \pm 1.68^{* *}$ \\
P1 & $91.5 \pm 2.57^{* *}$ \\
P4 & $202.3 \pm 11.2^{* *}$ \\
P7 & $251.7 \pm 13.5^{* *}$ \\
P14 & $397.1 \pm 15.5^{*}$ \\
P21 & $481.6 \pm 12.2$
\end{tabular}

Values are expressed as mean \pm SEM for each developmental age $(n=12)$. $* p<0.01$ and $* * p<0.001$ compared with P21 control. activity. CuZnSOD activity was significantly increased at E18 then declined at P1 to the P21 level $(p<0.05)$, remaining low at all postnatal ages (Fig. 2B).

Protein levels for catalase were also high at E18 and remained elevated above the P21 level throughout development (Fig. $3 A$ ). Catalase enzyme activity at E18 was $50 \%$ of P1 ( $p$ $<0.001$ ), and $\mathrm{P} 1$ was $70 \%$ of $\mathrm{P} 21$ activity. There was a slight decline at P4, followed by a steady increase to P21 control level (Fig. 3B).

Quantitation of brain GPx protein levels (Fig. 4A) was low at E18 and remained low until P4, followed by a 2-fold increase at P7, steadily increasing to the P21 level. GPx activity was initially low at E18, increasing 3-fold at P1 $(p<$ 0.001 ), then declined at $\mathrm{P} 4$ and $\mathrm{P} 21$ by 50 and $66 \%$, respectively. Fetal GPx activity was comparable to P14 and P21 levels; however, GPx activity at P4 and P7 was twice that of P21. Selenium-dependent GPx activity represented more than $50 \%$ of total GPx activity except at P1, when the nonseleniumdependent fraction showed a significant increase $(p<0.001)$. Selenium-dependent GPx activity paralleled total GPx activity at all ages except P21, when it represented only $25 \%$ of total GPx activity (Fig. 4B).

Reduced GSH level (Fig. 4) increased 1.5-fold between E18 and P1 $(p<0.01)$, with a further $25 \%$ increase between P1 and P21 control.

In summary, developmental changes shown in the perinatal and neonatal periods were 1) CuZnSOD and GPx protein levels were low at E18 and P1, at approximately 40 to $70 \%$ below P21 level; 2) MnSOD and catalase protein levels were high at E18 and P1, at approximately 25 to $50 \%$ above P21 level; 3) total SOD activity was high at E18 (2-fold increase) and P1 (3-fold increase) compared with P21, and total SOD activity paralleled the elevated MnSOD activity, whereas CuZnSOD activity remained low at all developmental ages; 4) catalase activity doubled from E18 to P1; 5) GPx activity was low at E18, with levels comparable to P21, but a 3-fold increase was noted at $\mathrm{P} 1$; and 6 ) reduced GSH level showed a 1.5 -fold increase between $\mathrm{E} 18$ and $\mathrm{P} 1$.

\section{DISCUSSION}

The current study was designed to determine the protein levels of the antioxidant enzymes and their corresponding enzyme activity throughout development from late fetal to early adulthood. The developmental changes in antioxidant enzyme activity in the postnatal rat brain have been previously described in relation to their subcellular localization using pooled homogenates at various ages (12). We hypothesized that the endogenous neuronal antioxidant defense system, which includes the SODs and GSH system, is developmentally regulated. Our data suggest that the antioxidant system may play a protective role during ontogeny, especially in the perinatal and neonatal periods when there is increased intracellular generation of ROS in response to changes in oxygen tension, leading to compensatory up-regulation of antioxidant protein levels and enzyme activities. This supports the view that there is a similar preparation for birth in the newborn brain as has been shown in the lung (13) and liver $(14,15)$, inasmuch as 

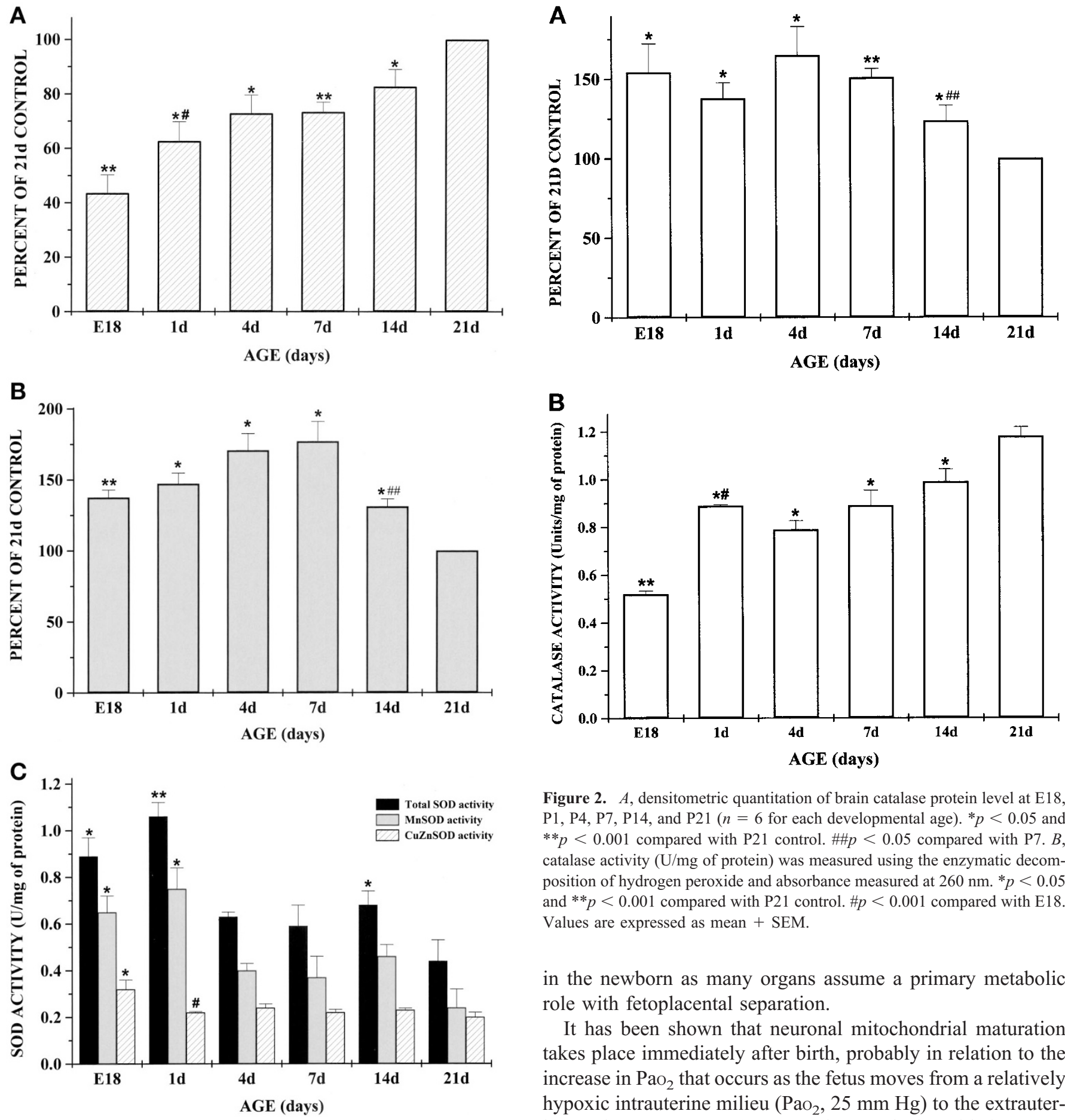

Figure 2. $A$, densitometric quantitation of brain catalase protein level at E18, P1, P4, P7, P14, and P21 ( $n=6$ for each developmental age). ${ }^{*} p<0.05$ and ${ }^{* *} p<0.001$ compared with P21 control. \#\#p $<0.05$ compared with P7. B, catalase activity (U/mg of protein) was measured using the enzymatic decomposition of hydrogen peroxide and absorbance measured at $260 \mathrm{~nm}$. ${ }^{*} p<0.05$ and $* * p<0.001$ compared with P21 control. $\# p<0.001$ compared with E18. Values are expressed as mean + SEM.

in the newborn as many organs assume a primary metabolic role with fetoplacental separation.

It has been shown that neuronal mitochondrial maturation takes place immediately after birth, probably in relation to the increase in $\mathrm{PaO}_{2}$ that occurs as the fetus moves from a relatively hypoxic intrauterine milieu $\left(\mathrm{PaO}_{2}, 25 \mathrm{~mm} \mathrm{Hg}\right)$ to the extrauterine environment $(16,17)$. Maturation results in oxidative stress as neuronal mitochondrial metabolism increases in response to

Figure 1. $A$, densitometric quantitation assessing brain $\mathrm{CuZnSOD}$ protein level at E18, P1, P4, P7, P14, and P21 ( $n=6$ for each developmental age). ${ }^{*} p$ $<0.05$ and ${ }^{* *} p<0.001$ compared with $\mathrm{P} 21$ control. $\# p<0.05$ compared with E18. $B$, densitometric quantitation of brain MnSOD protein level at E18, P1, P4, P7, P14, and P21 ( $n=6$ for each developmental age). ${ }^{*} p<0.01$ and $* * p$ $<0.001$ compared with P21 control. \#\#p $<0.02$ compared with P7. $C$, total SOD, CuZnSOD, and MnSOD activities (U/mg of protein). ${ }^{*} p<0.05$ and $* * p<0.001$ compared with P21 control. \#p $<0.05$ compared with E18. Values are expressed as mean + SEM.

birth is associated with significant oxidative stress and ROS generation (14) as a result of higher arterial oxygen content in the various organ systems, together with increased metabolism the availability of higher $\mathrm{PaO}_{2}$ postnatally. The mitochondria provide ATP for cellular homeostasis via oxidative phosphorylation and the electron transport chain under normal physiologic conditions and through these processes generate ROS in vivo. The resulting ROS production is compensated for by up-regulation of MnSOD at the site of its production, thereby aiding elimination, with continued maintenance of cellular homeostasis and cell membrane integrity.

GSH and all antioxidant enzymes except GPx demonstrated an increase in protein levels in late gestation and newborn periods. However, changes in protein concentration were not 

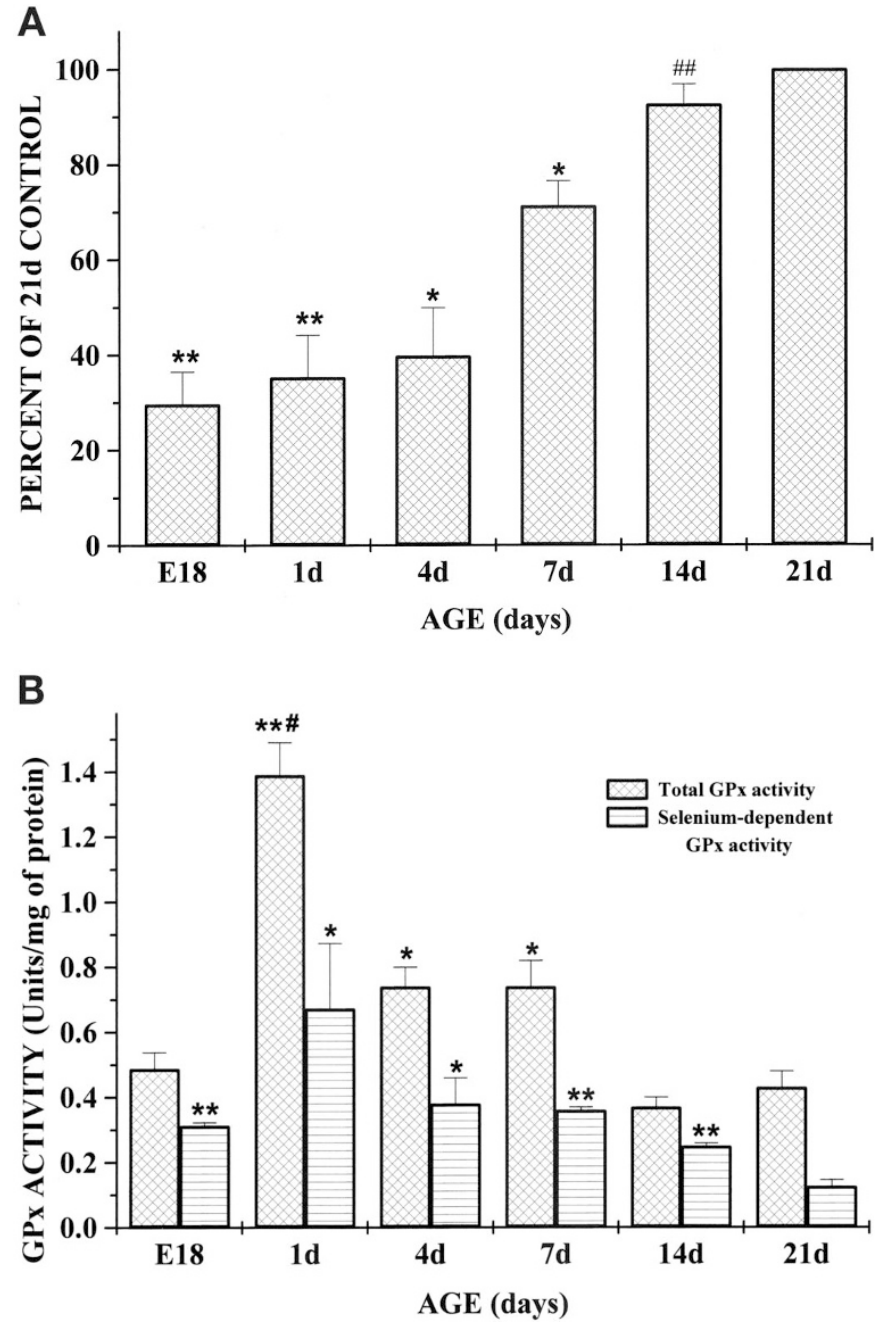

Figure 3. $A$, densitometric quantitation of brain GPx protein level at E18, P1, P4, P7, P14, and P21 ( $n=6$ for each developmental age). ${ }^{*} p<0.01$ and $* *$ $<0.001$ compared with P21 control. \#\#p $<0.01$ compared with P7. $B$, total and selenium-dependent GPx activity (U/mg of protein) was measured spectrophotometrically at $340 \mathrm{~nm}$ using the rate of NADPH oxidation. ${ }^{*} p<0.05$ and $*^{*} p<0.001$ compared with P21 control. $\# p<0.001$ compared with E18. Values are expressed as mean + SEM.

always paralleled by corresponding changes in activity. Despite a lack of surge in protein levels, GPx activity increased almost 3 -fold at $1 \mathrm{~d}$ of age. GPx is a selenium-containing enzyme, and selenium-dependent GPx is thought to represent the active fraction of the enzyme, whereas nonseleniumdependent GPx is normally quiescent in most tissues, where levels are usually one fourth of total activity although some variation has been found among species (18). However, Figure $3 B$ demonstrates that the nonselenium-dependent fraction (total GPx activity - selenium-dependent activity) in our study made up $>50 \%$ of the total GPx activity, which is approximately twice that found in many other tissues. The discrepancy between protein level and activity may be related to the activity of the nonselenium-dependent fraction of GPx, which reacts with $\mathrm{H}_{2} \mathrm{O}_{2}$ only at high concentrations (19) and therefore may play an important role in protecting the brain from oxidative stress. It is also interesting that although there was a surge in total SOD activity in late gestation and newborn periods, this

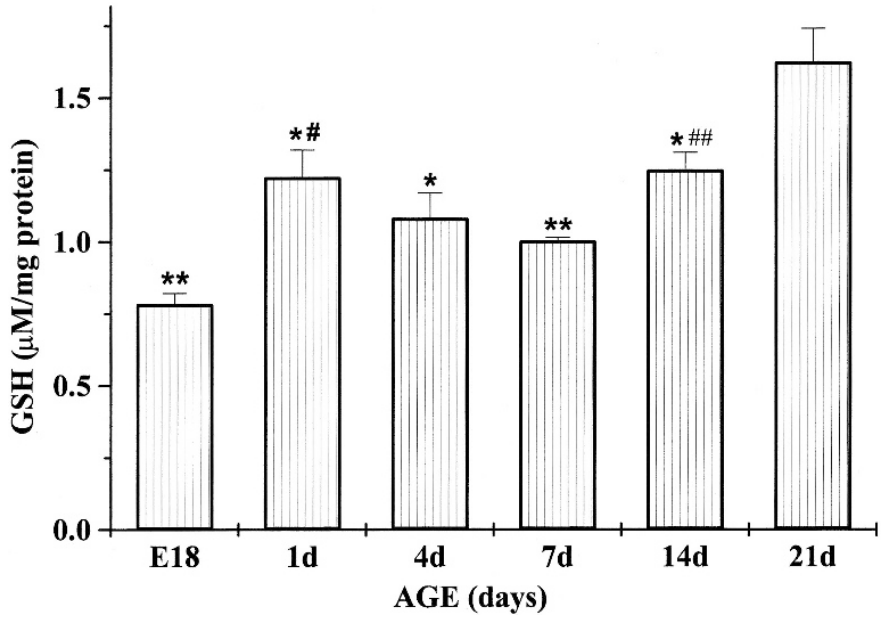

Figure 4. GSH level is shown in brain extracts obtained at E18, P1, P4, P7, P14, and P21 ( $n=6$ for each developmental age). ${ }^{*} p<0.05$ and ${ }^{* *} p<0.001$ compared with P21 control. $\# p<0.01$ compared with E18. \#\#p $<0.01$ compared with P7. Values are expressed as mean + SEM.

was caused mainly by increased MnSOD activity, whereas CuZnSOD activity remained relatively constant throughout development, except at P1 when a significant decline was noted. The discrepancy between CuZnSOD protein and enzyme activity is perhaps related to posttranslational modification. The activity of CuZnSOD requires copper. To limit spontaneous Fenton-type reactions, copper availability is limited to very low levels in vivo, and delivery of copper to this enzyme is the task of the copper chaperone for SOD (20). Thus, it is possible that expression of the copper chaperone for SOD is developmentally regulated with consequent modulation of CuZnSOD activity. However, further studies will be required to examine this possibility. In general, our current findings support the view of Mavelli et al. (12) that enzyme activities of SOD, catalase, and GPx do not uniformly parallel the development of aerobic metabolism during postnatal maturation. Generally, it is not surprising that MnSOD and catalase protein levels and activities are high in the brain as this is one of the tissues recognized for its high peroxisomal content, and mitochondrial MnSOD protein and enzyme activity parallels peroxisomal activity. On the other hand, cytosolic $\mathrm{CuZn}-$ SOD and GPx, although expressed at substantial levels, do not appear to be the main line of defense in the perinatal and neonatal periods. Teleologically, the newborn brain, like the liver (21) and endocrine system (22), appears to be primed physiologically for the surge in oxygen tension at birth by the up-regulation of the antioxidant system. We have further demonstrated that the cytosolic enzymes CuZnSOD and GPx show a steady increase from late fetal life to adulthood, with a significant increase noted between P7 and P14. It has previously been shown that increased oxygen free radicals are produced during the developmental process, especially during the period of myelination and synaptogenesis, which occurs at approximately $10-14 \mathrm{~d}$ in the mouse brain. Our results show a compensatory increase in cytosolic antioxidant enzyme protein levels between P7 and P14 to meet the metabolic demands that result in free radical generation. Surprisingly however, MnSOD and catalase, present in the energy-producing organelles 
of neuronal cells, display significantly decreased protein levels during this period of enhanced neural activity. This may be related to the role of uncoupling proteins in the mitochondria (23), which, by their interaction with SOD, may contribute to decreasing the concentration of ROS within the mitochondria as a feedback response to ROS production by the electron transport chain. This pathway appears to be functional at later developmental ages. Furthermore, catalase activity shows a steady increase to P21 value despite a decline in protein levels. The lower activities and higher protein levels at earlier developmental ages may be related to the fact that catalase may be dependent on a cofactor for activation, which may itself be developmentally regulated with low levels at earlier ages. As aging progresses beyond young adulthood, studies have shown a reduction in total antioxidant reserve and efficiency of the normally protective endogenous defense system throughout later life $(22,24,25)$. Neuronal cells therefore become more vulnerable to acute oxidative injury, and this contributes to the deleterious effect seen in older, more mature brains exposed to traumatic or ischemic brain injury. As the antioxidant reserve becomes depleted, the brain is especially vulnerable to oxidative stress because of its high oxidative metabolism using glucose and ATP as substrates. This vulnerability stems from its dependence on a constant exogenous supply of glucose and endogenously generated ATP, both of which are quickly depleted in response to various causes of brain injury, all of which involve pathways leading to free radical production.

Our data complement the results of others who have suggested attenuation of the effects of oxidative stress caused by ROS generation in the newborn brain over a variable period of time because of the total antioxidant reserve in both the white and gray matter of the brain (26). Nevertheless, the antioxidant system will eventually be overwhelmed if the cerebral insult is sustained for a long period, as may occur in hypoxia-ischemia of the newborn.

\section{CONCLUSIONS}

In conclusion, we suggest that, as the fetus moves from an in utero hypoxic to a relatively hyperoxic environment, with an approximately 4-fold elevation in oxygen concentration, the developmental changes in perinatal brain antioxidant enzymes are compensatory mechanisms aimed at protecting the newborn brain from oxidative stress.

\section{REFERENCES}

1. Chan PH 1994 Oxygen radicals in focal cerebral ischemia. Brain Pathol 4:59-65

2. Freeman BA, Crago JD 1982 Biology of disease: free radicals and tissue injury. Lab Invest 47:412-426

3. Halliwell B 1992 Reactive oxygen species and the central nervous system. J Neurochem 59:1609-1623

4. Boveris A, Chance B 1973 The mitochondrial generation of hydrogen peroxide. Biochem J 134:707-716

5. Ames BN, Shigenenga MT, Hagen M 1993 Oxidants, antioxidants and the degenerative diseases of aging. Proc Natl Acad Sci USA 90:7915-7922

6. Jain A, Martenson J, Stole E, Auld PAM, Meister A 1991 Glutathione deficiency leads to mitochondrial damage in brain. Proc Natl Acad Sci USA 88:1913-1917

7. Dringen R, Hamprecht B 1997 Involvement of glutathione peroxidase and catalase in the disposal of exogenous hydrogen peroxide by cultured astroglial cells. Brain Res 759:67-75

8. Bradford MM 1976 A rapid and sensitive method for the quantitation of microgram quantities of protein utilizing the principles of protein-dye binding. Anal Biochem $72: 248-254$

9. Anderson ME 1989 Enzymatic and chemical methods for the determination of glutathione. In: Dolphin D 1989 (eds) Glutathione: Chemical, Biochemical and Medical Aspects, Vol A. John Wiley and Sons, New York, pp 339-365

10. Aebi HE 1984 Catalase. In: Bergmeyer HU, Grabi M (eds) Methods of Enzymatic Analysis, Vol 3. Verlag Chemie, Weinheim, pp 273-286

11. Paglia DE, Valentine WN 1967 Studies in the qualitative characterization of erythrocyte glutathione peroxidase. J Lab Chem Med 70:158

12. Mavelli I, Rigo A, Federico R, Ciriolo MR, Rotilio G 1982 Superoxide dismutase, glutathione peroxidase and catalase in developing rat brain. Biochem J 204:535-540

13. Frank L, Sosenko IRS 1987 Prenatal development of lung antioxidant enzymes in four species. J Pediatr 110:106-110

14. Rickett GMW, Kelly FJ 1990 Developmental expression of antioxidant enzymes in guinea pig lung and liver. Development 108:331-336

15. De Haan JB, Tymms MJ, Cristiano F, Kola I 1994 Expression of copper/zinc superoxide dismutase and glutathione peroxidase in organs of developing mouse embryos, fetuses and neonates. Pediatr Res 35:188-196

16. Almeida A, Bolanos JP, Medina JM 1999 Nitric oxide mediates brain mitochondrial maturation immediately after birth. FEBS Lett 452:290-294

17. Juanes MC, Arizmendi C, Medina JM 1986 Attenuation of postnatal hypoxia in the premature newborn rat by maternal treatment with dexamethasone: its relationship with lung phospholipids content. Biol Neonate 50:337-344

18. Lawrence RA, Burk RF 1978 Species, tissue and subcellular distribution of nonselenium glutathione peroxidase activity. J Nutr 108:211-215

19. Lawrence RA, Burk RF 1976 Glutathione peroxidase activity in selenium-deficient rat liver. Biochem Biophys Res Commun 71:952-958

20. Casareno RL, Waggoner D, Gitlin JD 1998 The copper chaperone CCS directly interacts with copper/zinc superoxide dismutase. J Biol Chem 273:23625-23628

21. Greengard O 1970 The developmental formation of enzymes in the rat liver. In: Litwack G (eds) Biochemical Actions of Hormones. Academic Press, New York, pp 53-87

22. Moog F 1953 The influence of the pituitary-adrenal system on the differentiation of phosphatase in the duodenum of the suckling mouse. J Expl Zool 124:329

23. Echtay KS, Roussel D, St-Pierre J, Jekabsons MB, Cadenas S, Stuart JA, Harper JA, Roebuck SJ, Morrison A, Pickering S, Clapham JC, Brand MD 2002 Superoxide activates mitochondrial uncoupling proteins. Nature 415:96-99

24. Jung K, Henke W 1996 Developmental changes of antioxidant enzymes in kidney and liver from rats. Free Radic Biol Med 20:613-617

25. Azhar S, Cao L, Reaven E 1995 Alteration of the adrenal antioxidant defense system during aging in rats. J Clin Invest 96:1414-1424

26. Spector R, Eells J 1984 Deoxynucleoside and vitamin transport into the central nervous system. Fed Proc 43:196-200 